

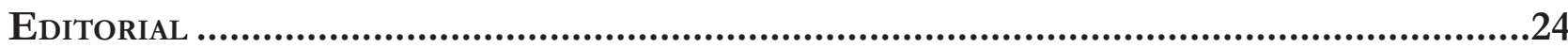

O Direito na fronteira da razão: Psicologia, neurociência e economia comportamental................... 24 Patrícia Perrone Campos Mello e Sergio Nojiri

I. NeURodireito: COGNIÇão, EMOÇÃo, JUÍZOS MORAIS E CIÊNCIA ..........................................26

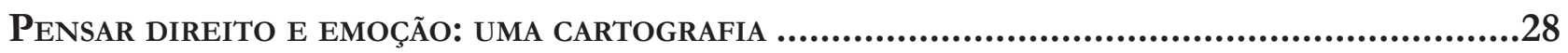

Nevita Maria Pessoa de Aquino Franca Luna

Neurodireito: o início, o fim E O MEIO

Carlos Marden e Leonardo Martins Wykrota

ENSAIO JURÍDICO SOBRE A RACIONALIDADE HUMANA: MAIORES, CAPAZES E IRRACIONAIS

André Perin Schmidt Neto e Eugênio Facchini Neto

DIVERGÊNCIAS DE PRINCÍPIO: ARGUMENTOS JURÍDICOS E MORAIS EM UM CENÁRIO DE DESACORDOS SOCIAIS

André Matos de Almeida Oliveira, Pâmela de Rezende Côrtes e Leonardo Martins Wykrota

CONSILIÊNCIA E A POSSIBILIDADE DO NEURODIREITO: DA DESCONFIANÇA À RECONCILIAÇÃO DISCIPLINAR.....

Thaís de Bessa Gontijo de Oliveira e Renato César Cardoso

MODELOS DE MORALIDADE

Molly J. Crockett

A INFELIZ BUSCA POR FELICIDADE No DiREITo

Úrsula Simões da Costa Cunha Vasconcellost, Noel Struchiner e Ivar Hannikainen

Além da liberdade: PersPeCtivas Em Nietzsche.

Lucas Costa de Oliveira

A mediaÇão de CONFlitos SOb a PERSPECTIVA do DESENVOLVIMENTO HUMANO: AS CONTRIBUIÇÕES DA PSICOLOGIA POSITIVA

Simone de Biazzi Ávila Batista da Silveira e Deise Brião Ferraz

Neuroimagiologia e aValiação de ResPonsabilidade

Nicole A. Vincent 
ANÁLISE CRÍTICA DA ORIENTAÇÃO DE CIDADÃOS COMO MÉTODO PARA OTIMIZAR DECISÕES PÚBLICAS POR MEIO DA TÉCNICA NUDGE.

Luciana Cristina Souza, Karen Tobias França Ramos e Sônia Carolina Romão Viana Perdigão

Políticas públicas e o deVer de monitoramento: “LEVANdo os Direitos A SÉrio". .252 Ana Paula de Barcellos

Nudges E POLÍticas PÚblicas: uM MECANISMO DE COMBATE AO TRABALHO EM CONDIÇÃo ANÁLOGA À DE ESCRAVO .267

Amanda Carolina Souza Silva, Débhora Renata Nunes Rodrigues e Saul Duarte Tibaldi

REDUZINDO A TRIBUTAÇÃO COGNITIVA: LIÇÕES COMPORTAMENTAIS PARA A DIMINUIÇÃO DOS EFEITOS PSICOLÓGICOS ADVERSOS DA POBREZA.............................................................288 Leandro Novais e Silva, Luiz Felipe Drummond Teixeira, Gabriel Salgueiro Soares e Otávio Augusto Andrade Santos

Políticas PÚBLICAS EM SUICÍDIO: DO PATERNALISMO CLÁSSICO AO PATERNALISMO LIBERTÁRIO E NUDGING

Davi de Paiva Costa Tangerino, Gabriel Cabral e Henrique Olive

Nudges COMO POLÍticA PÚbliCA PARA AUMENTAR O ESCASSO NÚMERO DE DOADORES DE ÓRGÃos PARA TRANSPLANTE

Roberta Marina Cioatto e Adriana de Alencar Gomes Pinheiro

Os PROGRAMAS DE INTEGRIDADE PARA CONTRATAÇÃO COM A ADMINISTRAÇÃO PÚBLICA ESTADUAL: NUDGE OU OBRIGAÇÃo LEGAL? UM OLHAR SOBRE AS DUAS PERSPECTIVAS .386

Cíntia Muniz Rebouças de Alencar Araripe e Raquel Cavalcanti Ramos Machado

Paternalismo libertário e Proteção JURídica do AMbiente: POR QUe PROTEger o AMBIENTE TAMBÉM DEVE SER PROTEGER AS LIBERDADES?

Mariana Carvalho Victor Coelho e Patryck de Araujo Ayala

Políticas PÚblicas baseadas EM EVIdÊNCIAS COMPORTAMENTAIS: REFLEXões A PARTIR do Projeto de Lei 488/2017 do Senado

Pâmela de Rezende Côrtes, André Matos de Almeida Oliveira e Fabiano Teodoro de Rezende Lara

III. ECONOMIA COMPORTAMENTAL: VIESES COGNITIVOS E POLÍTICAS PÚBLICAS .455

ECONOMIA COMPORTAMENTAL E DIREITO: A RACIONALIDADE EM MUDANÇA Marcia Carla Pereira Ribeiro e Victor Hugo Domingues

VIESES COGNITIVOS E DESENHO DE POLÍTICAS PÚBLICAS 
A neurociênCia da moralidade na tomada de DeCisões Jurídicas Complexas e No DESENHO DE POLÍTICAS PÚBLICAS

Erik Navarro Wolkart

Desvio de CARÁter ou SIMPLESMENTE HUMANO? ECONOMIA COMPORTAMENTAL APLICADA AO COMPORTAMENTO DESONESTO

Diana Orghian, Gabriel Cabral, André Pinto e Alessandra Fontana

Políticas Públicas e a ConcretizaÇão de direitos sociais: TOMAdA DE DECisão, ARQUITETURA DE ESCOLHAS E EFETIVIDADE

Ana Elizabeth Neirão Reymão e Ricardo dos Santos Caçapietra

BEHAVIORAL ECONOMICS E DIREITO DO CONSUMIDOR: NOVAS PERSPECTIVAS PARA O ENFRENTAMENTO DO SUPERENDIVIDAMENTO .568

Samir Alves Daura

A EDUCAÇÃo FORMAL PARA O CONSUMO É GARANTIA PARA UMA PRESENÇA REFLETIDA DO CONSUMIDOR NO MERCADO? UMA ANÁLISE COM BASE NA BEHAVIORAL LAW AND ECONOMICS (ECONOMIA COMPORTAMENTAL) 600

Marcia Carla Pereira Ribeiro e Edson Mitsuo Tiujo

LIBET, DETERMINISMO E CONSUMO: AS INFLUÊNCIAS DO MARKETING E A RELEVÂNCIA DA DELIBERAÇÃo CONSCIENTE NA SUPERAÇÃo CONDICIONAL DE HÁBITOS DE CONSUMO PERIGOSOS616 Émilien Vilas Boas Reis e Leonardo Cordeiro de Gusmão

CiÊNCIA DO DIREITO TRIBUTÁRIO, ECONOMIA COMPORTAMENTAL E EXTRAFISCALIDADE. .640 Hugo de Brito Machado Segundo

IV. CoMportamento JUdiCiAL: INFLUÊNCIA DE FATORES EXTRAJURÍDicos .660

FATORES METAPROCESSUAIS E SUAS INFLUÊNCIAS PARA A FORMAÇÃo DA DECISÃo JUDICIAL .662 Rogério Roberto Gonçalves de Abreu, Lúcio Grassi de Gouveia e Virgínia Colares

“A VIDA COMO ELA É": COMPORTAMENTO ESTRATÉGICO NAS CORTES Patrícia Perrone Campos Mello

A COMPOSIÇÃo do ÓRGão COLEGIAdo E SEUS EFEITOS NA TOMADA DE DECISÃo .720 André Garcia Leão Reis Valadares

Das 11 ilhas ao centro do arquipélago: os superpoderes do Presidente do STF DURANTE O RECESSO JUDICIAL E FÉRIAS .741 José Mário Wanderley Gomes Neto e Flávia Danielle Santiago Lima 
RAZÃo, EMOÇÃo E DELIBERAÇÃO: AS ADEQUAÇÕES REgIMENTAIS do SUPERIOR TribUNAL DE JUSTIÇA PARA A FORMAÇÃo DE PRECEDENTES EFICAZES

Peter Panutto e Lana Olivi Chaim

Heurística de ancoragem e fiXaÇÃo de danos morais em JUizados especiais Cíveis no Rio DE JANEIRO: UMA NOVA ANÁLISE 778

Fernando Leal e Leandro Molhano Ribeiro

LA PROTECCIÓN DE LOS DERECHOS POLÍTICOS FRENTE A LAS FUNCIONES DISCIPLINARIAS DE LAS AUTORIDADES ADMINISTRATIVAS: SUBSIDIARIEDAD Y DEFERENCIA EN EL SISTEMA INTERAMERICANO DE DERECHOS HUMANOS Jorge Ernesto Roa Roa

V. A influênCia do gÊNERo no PROCESSO DECisório JUdiCial

Como os Juízes decidem os Casos de estupro? ANALISANDo SENTENÇAS SOb A PERSPECTIVA DE VIESES E ESTEREÓTIPOS DE GÊNERO 826 Gabriela Perissinotto de Almeida e Sérgio Nojiri

GÊNERO E COMPORTAMENTO JUDICIAL NO SUPREMO TRIBUNAL FEDERAL: OS MINISTROS CONFIAM MENOS EM RELATORAS MULHERES?

Juliana Cesario Alvim Gomes, Rafaela Nogueira e Diego Werneck Arguelhes

Hércules, Hermes e a Pequena Sereia: uma reflexão sobre estereótipos de gênero, SUBPRESENTAÇÃo DAS MULHERES NOS TRIBUNAIS E (I)LEGITIMIDADE DEMOCRÁTICA DO PODER JUDICIÁRIO. .878 Jane Reis Gonçalves Pereira e Renan Medeiros de Oliveira

Prisão Cautelar de gestantes: análise do Fundamento filosófico da decisão do Habeas CoRpus N. 143.641 912

Artur César Souza e Giovania Tatibana de Souza

VI. Neurodireito APlicado ao direito E Ao Processo PENAL....................................926

CÉREbros QUe PUNEM: UMA REVISÃo CRÍTICA DA NEURoCIÊNCIA DA PUNIÇÃo .....................928 Ricardo de Lins e Horta

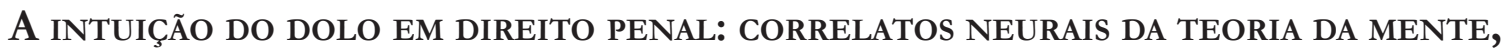
RACIOCÍNIO INDUTIVO E A GARANTIA DA CONVICÇÃO JUSTIFICADA. .946 Thiago Dias de Matos Diniz e Renato César Cardoso

As COMUNIDADES EPISTÊMICAS PENAIS E A PRODUÇÃo LEGISLATIVA EM MATÉRIA CRIMINAL..... 961 Stéphane Enguéléguélé 
DELINQUÊNCIA JUVENIL: RELAÇÕES ENTRE DESENVOLVIMENTO, FUNÇÕES EXECUTIVAS E COMPORTAMENTO SOCIAL NA ADOLESCÊNCIA .

André Vilela Komatsu, Rafaelle CS Costa e Marina Rezende Bazon

Límites TEMPORALES A LAS PENAS PRIVATIVAS DE LIBERTAD ATENDIENDO AL DESARROLLO PSICOSOCIAL.

Silvio Cuneo Nash

NEURolaw E AS PERSPECTIVAS PARA UMA ANÁLISE OBJETIVA DO COMPORTAMENTO SUGESTIONADO: REPERCUSSÃO DAS FALSAS MEMÓRIAS NA ESFERA PENAL

Mariana Dionísio de Andrade, Marina Andrade Cartaxo e Rafael Gonçalves Mota

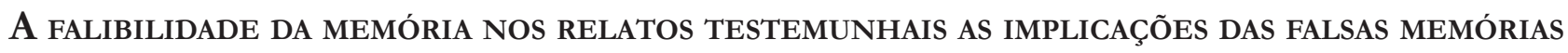
NO CONTEXTO DOS CRIMES CONTRA A DIGNIDADE SEXUAL

Caroline Navas Viana

A (IR)REPETIBILIDADE dA PROVA PENAL DEPENDENTE DA MEMÓRIA: UMA DisCUSSÃo COM BASE NA PSICOLOGIA DO TESTEMUNHO. 1058

William Weber Cecconello, Gustavo Noronha de Avila e Lilian Milnitsky Stein 


\section{Prisão cautelar de gestantes: análise do fundamento filosófico da decisão do Habeas Corpus n. $143.641^{*}$}

\author{
Precautionary prison of pregnant: analysis of \\ the philosophical foundation of Habeas Corpus \\ decision n. 143.641
}

\author{
Artur César Souza** \\ Giovania Tatibana de Souza***
}

* Recebido em 25/04/2018 Aprovado em 21/05/2018

** Pós-Doutor pelas seguintes Universidades: a) Università Statale di Milano; b) Universidad de Valencia; c) Faculdade de Direito da Universidade de Lisboa; d) Universidade Federal de Santa Catarina - UFSC. Doutor em Direito das Relações Sociais pela Universidade Federal do Paraná. Doutorando em Filosofia pela Universidade de Barcelona. Professor do Curso de Doutorado e Mestrado na UNIMAR-Universidade de Marília. Juiz Federal convocado, no Tribunal Regional Federal da $4^{\mathrm{a}}$ Região. Email: arturcesarsouza@gmail.com

*** Professora da UNOPAR - Universidade Norte do Paraná. Especialista em Direito Processual pela UEL - Universidade Estadual de Londrina. Advogada.

Email: geovaniatatibana@gmail.com

\section{Resumo}

O Supremo Tribunal Federal, em 21 de fevereiro de 2018, ao proferir decisão no Habeas Corpus n. 143.611, em favor das mulheres presas preventivamente e que ostentam a condição de gestantes, de puérperas ou de mães de crianças sob sua responsabilidade, deixou evidenciado, de certa forma, quais seriam os fundamentos da dogmática jurídica penal, constitucional, criminológica, sociológica e do direito das gentes que serviram de base para a proteção coletiva das pacientes. O objetivo do presente trabalho, porém, é encontrar, nas entrelinhas da referida, decisão judicial um fundamento ético filosófico que possa se compatibilizar com o resultado do julgamento. Para tanto, utilizando-se de um método de revisão doutrinária, analítico dedutivo, realiza-se um diálogo interdisciplinar entre a ciência jurídica e a ética filosófica, para, ao final, tentar demonstrar-se que, em todos os discursos linguísticos, ainda que jurídicos, há um fundamento ético filosófico que contribui, ativamente, para o resultado a ser alcançado.

Palavras-chaves: Decisão judicial. Fundamento. Ética filosófica. Racionalidade do outro.

\section{Abstract}

The Supreme Federal Court, on February 21, 2018, when rendering a ruling in Habeas Corpus n. 143,611, in favor of women preemptively detained and bearing the status of pregnant women, mothers of children under their responsibility, has left to a certain extent what would be the basis of criminal, constitutional, criminological, sociological and law which served as the basis for the collective protection of patients. The objective of the present work, however, is to find in the lines of the aforementioned judicial decision an ethical philosophical foundation that can be compatible with the result of the judgment. To do so, using an analytical deductive method, an interdisciplinary dialogue between legal science and philosophical ethics is done, in order to try to demonstrate that in all linguistic discourses, even if 
legal, there is a philosophical ethical foundation which actively contributes to the outcome to be achieved.

Keywords: Judicial decision. Background. Philosophical ethics. Rationality of the other.

\section{INTRODUÇÃo}

Eloísa Machado de Almeida, Bruna Soares Angotti, André Ferreira, Nathalie Fragoso e Hilem Oliveira, membros do Coletivo de Advogados em Direitos Humanos, impetraram Habeas Corpus Coletivo n. 143.641, com pedido de medida liminar, perante o Supremo Tribunal Federal, em favor de todas as mulheres presas, preventivamente, que ostentam a condição de gestantes, de puérperas ou de mães de crianças sob sua responsabilidade, bem como em nome das próprias crianças.

O Supremo Tribunal Federal, no dia 20 de fevereiro de 2018, em decisão 'paradigmática' e inédita, de relatoria do Ministro Ricardo Lewandowski, concedeu a ordem de Habeas Corpus para o fim de determinar a substituição da prisão preventiva pela domiciliar, sem prejuízo da aplicação concomitante das medidas alternativas no art. 319 do Código de Processo Penal — de todas as mulheres presas, gestantes, puérperas, ou mães de crianças e deficientes sob sua guarda, nos termos do art. $2^{\circ}$ do Estatuto da Criança e do Adolescente e da Convenção sobre Direitos das Pessoas com Deficiências (Decreto Legislativo n. 186/2008 e Lei n. 13.146/2015).

É possível extrair-se do discurso linguístico produzido no inteiro teor do acórdão os fundamentos jurídicos da dogmática penal e do direito constitucional, assim como os fundamentos sociológicos, criminológicos, e do direito das gentes que serviram de base para a proteção das mulheres presas preventivamente.

Porém, o objetivo do presente trabalho é ir um pouco mais além. Pretende-se analisar qual o fundamento ético filosófico que mais se compatibiliza com a concessão da ordem de Habeas Corpus coletivo.

A escolha de uma perspectiva ética filosófica, e que se indica no presente trabalho, não significa afirmar que não haja outras concepções éticas também justificáveis. O que se pretende demonstrar justamente é que o discurso linguístico realizado pela ciência jurídica e pela filosofia não está desconectado ou isolado, mas, sim, muito bem entrelaçado e sugestionado.

\section{Os FUNDAMENTOS APARENTES E EXPRESSAMENTE CONSIGNADOS NA DECISÃO PROFERIDA NO Habeas Corpus n. 143.641}

O presente trabalho tem por objetivo analisar os fundamentos que deram sustentação à decisão proferida no Habeas Corpus n. 143.641, em especial o fundamento filosófico. No presente tópico, pretende-se indicar os fundamentos aparentes e expressamente consignados nos votos e no acórdão da decisão objeto do presente estudo, a saber:

\subsection{Fundamento com base na dogmática penal}

A decisão proferida no Habeas Corpus n. 143.641 do Supremo Tribunal deixa muito bem evidenciado quais sãos os fundamentos jurídicos que justificam a proteção das mulheres presas, preventivamente, e que ostentam a condição de gestantes.

O fundamento jurídico penal respalda-se no argumento de que, com a entrada em vigor da Lei n. 13.257/2016, que alterou o Código de Processo Penal, há possibilidade de substituição da prisão preventiva 
por prisão domiciliar para gestantes e mães de crianças.

Além disso, a Lei n. 11.942/2009, que promoveu mudanças na Lei de Execução Penal, estabelece os seguintes direitos subjetivos à mulher: a) acompanhamento médico à mulher, principalmente no pré-natal e no pós-parto, extensivo ao recém-nascido; b) estabelecimentos penais destinados a mulheres serão dotados de berçário, onde as condenadas possam cuidar de seus filhos, inclusive, amamentá-los, no mínimo, até 6 (seis) meses de idade; c) a penitenciária de mulheres será dotada de seção para gestante e parturiente e de creche para abrigar crianças maiores de 6 (seis) meses e menores de 7 (sete) anos, com a finalidade de assistir a criança desamparada cuja responsável estiver presa, inclusive, à presa provisória (art. 42 da Lei de Execução Penal).

\subsection{Fundamento jurídico constitucional}

Além das regras jurídicas penais acima indicadas, a decisão, também, se respalda em princípios jurídicos de direito constitucional, a saber: a aplicação do princípio da intranscendência, segundo o qual a pena não pode passar da pessoa do condenado, e do princípio da primazia dos direitos da criança, da vedação de penas cruéis e da individualização da pena.

A forte violação de direitos fundamentais, alcançando a transgressão à dignidade da pessoa humana e ao próprio mínimo existencial justifica a atuação do Poder Judiciário em prol da mulher preventivamente presa. ${ }^{1}$

A decisão proferida pelo Supremo Tribunal Federal nada mais fez do que dar concreção ao que a Constituição, em sua redação original, já determinava: a) - art. $5^{\circ}$, II - ninguém será submetido à tortura nem a tratamento desumano ou degradante; b) - art. $5^{\circ}$, XLI - a lei punirá qualquer discriminação atentatória dos direitos e liberdades fundamentais; c) art. $5^{\circ}$, XLV - nenhuma pena passará da pessoa do condenado [...]; d) - art. $5^{\circ}, \mathrm{L}$ - às presidiárias serão asseguradas condições para que possam permanecer com seus filhos durante o período de amamentação; e) - art. $5^{\circ}$, XLVIII - a pena será cumprida em estabelecimentos distintos, de acordo com a natureza do delito, a idade e o sexo do apenado; f) - art. $5^{\circ}$, XLIX - é assegurado aos presos o respeito à integridade física e moral.

\subsection{Fundamento criminológico}

O fundamento criminológico teve papel preponderante na decisão proferida pelo Supremo Tribunal Federal, em especial quando se asseverou que a política criminal responsável pelo expressivo encarceramento feminino é discriminatória e seletiva, impactando, de forma desproporcional, as mulheres pobres e suas famílias.

O Levantamento Nacional de Informações Penitenciárias - INFOPEN Mulheres², preconiza que “a população absoluta de mulheres encarceradas no sistema penitenciário cresceu $567 \%$ entre os anos 2000 e 2014", incremento muito superior ao da população masculina, que, ainda assim, aumentou exagerados 220\% no mesmo período, a demonstrar a tendência geral de aumento do encarceramento no Brasil. Especificamente no tocante à prisão provisória, "enquanto 52\% das unidades masculinas são destinadas ao recolhimento de presos provisórios, apenas $27 \%$ das unidades femininas têm esta finalidade", apesar de 30,1\% da população prisional feminina ser provisória.

1 "A dignidade humana é requisito essencial do regime democrático brasileiro tendo em vista seu caráter ideal abstrato que orienta as decisões do Poder Público no sentido de implementar políticas públicas que efetivem direitos fundamentais e garantam a qualidade de vida dos cidadãos". SOUZA, Luciana Cristina. Dignidade humana na webesfera governamental brasileira. Revista Brasileira de Políticas Públicas. v. 7, n. 3, dez. 2017. p. 203.

2 BRASIL. Ministério da Justiça. Infopen Mulheres. Levantamento nacional de informações penitenciárias. 2014. p. 18-19. Disponível em: $<$ https://www.justica.gov.br/news/estudo-traca-perfil-da-populacao-penitenciaria-feminina-no-brasil/relatorio-infopen-mulheres. pdf>. Acesso em: 7 jun. 2018. 
Outro dado de fundamental interesse diz respeito ao fato de que $68 \%$ das mulheres estão presas por crimes relacionados ao tráfico de entorpecentes, delitos que, na grande maioria dos casos, não envolvem violência nem grave ameaça a pessoas, e cuja repressão recai, não raro, sobre a parcela mais vulnerável da população, em especial sobre os pequenos traficantes, quase sempre mulheres, vulgarmente denominadas de "mulas do tráfico". ${ }^{3}$ Nesses casos, quase sempre, como revelam os estudos especializados, a prisão preventiva mostra-se desnecessária, já que a prisão domiciliar prevista no art. 318 do Código de Processo Penal pode, com a devida fiscalização, impedir a reiteração criminosa.

O retrato que ora se vai delineando em tudo coincide com os documentos produzidos no âmbito do sistema universal de direitos humanos sobre o tema (vide, em especial, o texto destinado a orientar os trabalhos da Força-Tarefa do Sistema ONU (Organizações das Nações Unidas) sobre o Crime Organizado e o Tráfico de Drogas, como Ameaças à Segurança e Estabilidade. UN Women. A genderperspective on the impact of drug use, the drug trade, and drug control regimes, 2014): o envolvimento das mulheres no uso e tráfico de drogas reflete seu déficit de oportunidades econômicas e status político. Quando se engajam em atividades ilícitas, são relegadas às mesmas posições vulneráveis que pavimentaram o caminho desse engajamento. Quando alvos da persecução penal, deparam-se com um sistema judiciário que desacredita seus testemunhos e com a atribuição de penas ou medidas cautelares que negligenciam suas condições particulares como mulheres ${ }^{4}$.

\subsection{Fundamento no direito das gentes}

A decisão proferida pelo Supremo Tribunal Federal encontra justificativa em normas e acordos de direito internacional. Enfatiza-se o cabimento de habeas corpus coletivo na defesa da liberdade de locomoção de determinados grupos de pessoas, com fulcro na garantia de acesso à Justiça, e considerando o caráter sistemático de práticas que resultam em violação maciça de direitos. Invoca-se o art. 25, I, da Convenção Americana de Direitos Humanos, que garante o direito a um instrumento processual simples, rápido e efetivo, apto a tutelar direitos fundamentais lesionados ou ameaçados.

O Brasil não tem sido capaz de garantir cuidados relativos à maternidade nem mesmo às mulheres que não estão em situação prisional. Nesse sentido, relembre-se o "caso Alyne Pimentel”, que representou a

primeira denúncia sobre mortalidade materna acolhida pelo Comitê para a Eliminação de todas as Formas de Discriminação contra a Mulher [...] incumbido de monitorar o cumprimento pelos Estadosparte da Convenção relativa aos Direitos das Mulheres, adotada pelas Nações Unidas em 1979", tratando-se da "única 'condenação' do Estado brasileiro proveniente de um órgão do Sistema Universal de Direitos Humanos.

O cuidado com a saúde maternal é considerado como uma das prioridades que deve ser observada pelos distintos países no que concerne ao seu compromisso com a promoção de desenvolvimento, conforme consta do Objetivo de Desenvolvimento do Milênio - ODM no 5 (melhorar a saúde materna) e do Objetivo de Desenvolvimento Sustentável - ODS no 5 (alcançar a igualdade de gênero e empoderar todas as mulheres e meninas), ambos documentos subscritos no âmbito da Organização das Nações Unidas. Aliás, a reiteração da ênfase conferida pela ONU sobre o tema foi reforçada nos ODSs justamente porque, durante o tempo em que vigeram os ODMs (2000-2015), foi possível constatar "a falta de avanço em algumas áreas, particularmente aquelas relacionadas com saúde materna, neonatal e infantil e saúde reprodutiva".

3 SOARES, B. M.; ILGENFRITZ, I. Prisioneiras: vida e violência atrás das grades. Rio de Janeiro: Garamond, 2002. p. 22.

4 UN WOMEN. A gender perspective on the impact of drug use, the drug trade, and drug control regimes. 2014. p. 34-35. Disponível em: <https://www.unodc.org/documents/ungass2016/Contributions/UN/Gender_and_Drugs_-_UN_Women_Policy_Brief.pdf>. Acesso em: 7 jun. 2018.

5 ALBUQUERQUE, Aline S. de Oliveira; BARROS, Julia Schirmer. Caso Alyne Pimentel: uma análise à luz da abordagem baseada em direitos humanos. Revista do Instituto Brasileiro de Direitos Humanos, Fortaleza, n. 12, jul. 2016. p. 11.

6 MACHADO FILHO, Haroldo. Dos objetivos do milênio aos objetivos do desenvolvimento sustentável: lições aprendidas e desafios. In: UNLÃO Europeia, Brasil e os desafios da agenda do desenvolvimento sustentável. Rio de Janeiro: Konrad Adenauer Stiftung, 
Faz-se referência, ainda, às Regras das Nações Unidas para o Tratamento de Mulheres Presas e Medidas Não Privativas de Liberdade para Mulheres Infratoras, também conhecidas como Regras de Bangkok.

Apesar de o Governo Brasileiro ter participado, ativamente, das negociações para a elaboração das Regras de Bangkok e a sua aprovação na Assembleia Geral das Nações Unidas, até o momento, elas não foram plasmadas em políticas públicas consistentes, em nosso país, sinalizando, ainda, o quanto carece de fomento a implementação e a internalização eficaz pelo Brasil das normas de direito internacional dos direitos humanos. E cumprir essa regra é um compromisso internacional, Revisado Habeas Corpuns 143641/SP, assumido pelo Brasil. Embora se reconheça a necessidade de impulsionar a criação de políticas públicas de alternativas à aplicação de penas de prisão às mulheres, é estratégico abordar o problema primeiramente sob o viés da redução do encarceramento feminino provisório. De acordo com as Regras de Bangkok, deve ser priorizada solução judicial que facilite a utilização de alternativas penais ao encarceramento, principalmente para as hipóteses em que ainda não haja decisão condenatória transitada em julgado".

\subsection{Fundamento político ou de gestão política}

Extrai-se da decisão proferida pelo Supremo Tribunal Federal alguns fundamentos políticos ou de gestão política. Os estabelecimentos prisionais não são preparados, de forma adequada, para atender à mulher presa, especialmente a gestante e a que é mãe.

Segundo dados oficiais, faltam berçários e centros materno-infantis e que, em razão disso, as crianças se ressentem da falta de condições propícias para seu desenvolvimento, o que não somente afeta sua capacidade de aprendizagem e de socialização, como também vulnera, gravemente, seus direitos constitucionais, convencionais e legais.

Embora a Lei de Execução Penal (LEP) determine como obrigatória, nos estabelecimentos penais, a presença de instalações para atendimento a gestantes e crianças, essas disposições legais vêm sendo sistematicamente desrespeitadas. A constatação de deficiência estrutural, especificamente em relação à situação da mulher presa, foi reconhecida na Ação de Descumprimento de Preceito Fundamental (ADPF n. 347 MC/ $\mathrm{DF}){ }^{7}$

A ausência de medidas legislativas, administrativas e orçamentárias eficazes representa falha estrutural a gerar tanto a violação sistemática dos direitos quanto a perpetuação e o agravamento da situação. A inércia não é de uma única autoridade pública — do Legislativo ou do Executivo de uma particular unidade federativa -, e sim do funcionamento deficiente do Estado como um todo. Os poderes, órgãos e entidades federais e estaduais, em conjunto, vêm se mantendo incapazes e manifestando verdadeira falta de vontade em buscar superar ou reduzir o quadro objetivo de inconstitucionalidade. Faltam sensibilidade legislativa e motivação política do Executivo. ${ }^{8}$

\footnotetext{
2016. p. 88.

7 Conforme bem afirmou o Ministro Marco Aurélio, em seu voto na ADPF n. 347 MC/DF: "A ausência de medidas legislativas, administrativas e orçamentárias eficazes representa falha estrutural a gerar tanto a violação sistemática dos direitos, quanto a perpetuação e o agravamento da situação. A inércia, como dito, não é de uma única autoridade pública - do Legislativo ou do Executivo de uma particular unidade federativa -, e sim do funcionamento deficiente do Estado como um todo. Os poderes, órgãos e entidades federais e estaduais, em conjunto, vêm se mantendo incapazes e manifestando verdadeira falta de vontade em buscar superar ou reduzir o quadro objetivo de inconstitucionalidade. Faltam sensibilidade legislativa e motivação política do Executivo. É possível apontar a responsabilidade do Judiciário no que $41 \%$ desses presos, aproximadamente, estão sob custódia provisória. Pesquisas demonstram que, julgados, a maioria alcança a absolvição ou a condenação a penas alternativas, surgindo, assim, o equívoco da chamada 'cultura do encarceramento"'.

$8 \mathrm{Na}$ verdade, "qualquer análise que possa ser feita do sistema penitenciário brasileiro indica a existência de uma situação, absolutamente, desastrosa e abusiva. Desastrosa, na perspectiva da existência de um sistema anacrônico, de matizes medievais, sem condições estruturais básicas para atendimento das regras constitucionais ou dos direitos fundamentais dos presos. Abusiva porque o simples ingresso de um apenado em um cárcere desse sistema, ressalvadas algumas situações excepcionais que felizmente ainda podem ser encontradas, já indica que a possibilidade será quase total de que venha a ser submetidos a atos de violência a ameaças, a
} 
Mais graves, porém, são os dados sobre infraestrutura relativa à maternidade no interior dos estabelecimentos prisionais, sobre os quais cabe apontar que: a) nos estabelecimentos femininos, apenas 34\% dispõem de cela ou dormitório adequado para gestantes, apenas 32\% dispõem de berçário ou centro de referência materno infantil e apenas 5\% dispõem de creche (INFOPEN Mulheres); (b) nos estabelecimentos mistos, apenas $6 \%$ das unidades dispõem de espaço específico para a custódia de gestantes, apenas 3\% dispõem de berçário ou centro de referência materno infantil e nenhum dispõe de creche?.

\subsection{Fundamento sócio/econômico}

Verificam-se, na decisão do Supremo Tribunal Federal, alguns fundamentos econômicos. Destaca-se a vulnerabilidade socioeconômica das mulheres presas preventivamente no Brasil.

Nesse diapasão, ressaltam-se dados da pesquisa "Panorama de Acesso a 4 Revisado Habeas Corpus 143641/SP Justiça no Brasil, 2004 a 2009”"10, os quais demonstram que, abaixo de determinado nível de escolaridade e renda, o acesso à Justiça praticamente não se concretiza. Tal pesquisa, dentre outras revelações, ressalta o quanto esse acesso, como direito de segunda geração ou dimensão, tem encontrado dificuldades para se realizar no Brasil, esbarrando, sobretudo, no desalento, ou seja, nas dificuldades relacionadas a custo, distância e desconhecimento que impedem as pessoas mais vulneráveis de alcançar o efetivo acesso à Justiça.

\section{FundAMENTO ÉtICO-FILOSÓFICO}

A partir deste momento, pretende-se aviventar certa concepção ética filosófica que possa ter servido de inspiração para a prolação da decisão no Habeas Corpus n. 143.611, levando-se em conta todas as circunstâncias já observadas nos fundamentos acima indicados.

O fio condutor do presente trabalho, a partir desse momento, é justamente os pressupostos filosóficos fundamentais que justificam a proteção das mulheres presas preventivamente que ostentam a condição de gestantes, de puérperas ou de mães de crianças sob sua responsabilidade, bem como em nome das próprias crianças.

Pretende-se, nessa última etapa do trabalho, percorrer um caminho diametralmente oposto daquele traçado por Elio Fazzalari, quando, ao analisar os princípios reguladores do processo jurisdicional, peremptoriamente, afirmou que o juiz não pode, na relação jurídica processual, reconhecer o "outro", reconhecer a debilidade econômica, cultural, social ou mesmo psicológica do "outro", pois, se assim proceder, poderá produzir possíveis decisões iníquas. ${ }^{11}$

cooptação por organizações criminosas, a contraírem doenças e a não receberem qualquer ação efetiva que pudesse implicar a sua futura reinserção social”. ROCHA, Lilian Rose Lemos; CARDOZO, José Eduardo. Precariedade do sistema penitenciário brasileiro como base temática para a proibição ou legalização das drogas. Revista Brasileira de Políticas Públicas, v. 7, n.3, dez. 2017.

9 BRASIL. Ministério da Justiça. Infopen Mulheres. Levantamento nacional de informações penitenciárias. 2014. p. 18-19. Disponível em: $<$ https://www.justica.gov.br/news/estudo-traca-perfil-da-populacao-penitenciaria-feminina-no-brasil/relatorio-infopen-mulheres. pdf>. Acesso em: 7 jun. 2018.

10 BRASIL. Conselho Nacional de Justiça. PANORAMA de Acesso a 4 Revisado Habeas Corpus 143641/ SP Justiça no Brasil, 2004 a 2009. Brasília: Conselho Nacional de Justiça, 2011.

11 "Potrebbe sembrare al profano o all'osservatore superficiale che al giudice incomba almeno di sopperire alla debolezza del non abbiente. Ma no è così. La Carta fondamentale è chiarissima nel volere che a quel cittadino siano forniti, mediante appositi istituti, mezzi d'assistenza per agire e difendersi in giudizio; ma, proprio per questo, essa non consente che, in difetto di mezzi e permanendo l'inadempienza costituzionale dello Stato, il giudice manifesti una qualsiasi parzialità nei confronti del non abbiente: secondo la Costituzione questi deve comparire davanti a lui già munito dell'usbergo che lo metta al sicuro dalla sua stessa debolezza e che renda omnimamente superflui poteri, per così dire suppletori, del giudice in di lui vantaggio. [...]. Chè, se invece la norma sostanziale non contempli o non supplisca a quella debolezza, il giudice non può, in sede di giudizio di diritto, abbandonarsi al dubbio o cedere alla tentazione di scegliere, come metro di giudizio, un altro valore (o, più semplicemente, la propria personale 
Apesar da admiração e do respeito que se deve ter pelo trabalho intelectual do eminente processualista italiano, não se pode deixar de considerar que sua visão está inserida na totalidade racional da Europa continental, o que favorece a postulação de um juiz totalmente divorciado das necessidades e das precariedades humanas, e a perspectiva de uma leitura da imparcialidade apenas no âmbito abstrato e meramente formal.

Realçando-se as particularidades da periferia do mundo, especialmente as desigualdades materiais da América Latina, não se pode permanecer numa visão meramente formal e abstrata da imparcialidade do juiz. Diante desses aspectos materiais, há necessidade de se reconhecer a "alteridade do outro". ${ }^{12}$

O Estado-Juiz deve atuar de modo tal que todos os sujeitos processuais tenham iguais perspectivas de levar adiante suas pretensões. Nessa alternativa, o Estado-Juiz:

[...] debe tratar desigualmente a sus ciudadanos, de modo que — después de la actuación del estado todos ellos tengan iguales probabilidades de llevar a cabo su plan de vida. Puesto que el estado actúa en este caso me parece adecuado rebautizar a esta alternativa denominándola neutralidad positiva. ${ }^{13}$

São as próprias conjecturas estruturais que impedem que as pessoas sejam iguais entre si. Para Max Weber, as pessoas são desigualmente dotadas do ponto de vista físico, intelectual e moral. Na verdade, há uma verdadeira loteria genética no ponto de partida da existência humana: “[...] os genes que recebemos dependem, no sentido exato do termo, de um cálculo de probabilidades". ${ }^{14}$

Segundo Enrique Dussel:

Ninguém surge do acaso ou aparece por geração espontânea. Todo homem, mesmo o mais simples camponês ou o mais humilde trabalhador urbano, tem história. É fruto de uma herança genética, de um contexto sócio-político-econômico-cultural e de uma opção pessoal assumida e trabalhada há anos. O resultado de tudo isto é o homem na sua concretude. ${ }^{15}$

E, para se visualizar a pessoa em sua concretude, não basta o desenvolvimento de um processo meramente formal, sem que se pense numa ética de conteúdo ou material a ser introduzida na relação jurídica processual, sem que se perceba as diferenças empíricas entre os sujeitos da relação jurídica processual penal ou civil.

Piero Pajardi ressaltou: “[...] quanto di humanità e di socialità ed ancora quanto di valori etici e di fattori esistenziali stia dietro l' apparente freddezza tecnica di una norma processuale". ${ }^{16}$

Para Fábio Konder Comparato, por muito tempo, a justiça foi concebida more geometricu, como ente exclusivo da razão, sem qualquer vínculo com a sensibilidade valorativa. Aliás, sua representação simbólica insere-se numa personagem cega, neutra, implacável e impassível. Contudo, “[...] a verdadeira justiça, muito ao contrário, é sempre parcialíssima. Ela não se coaduna com equidistâncias formais nem se contenta com equilíbrio de circunstâncias". ${ }^{17}$

valutazione); nè può travisare quella norma. [...]." FAZZALARI, Elio. La imparzialità del giudice. Rivista di Dirito Processuale, Padova, Cedam, n. 2, p. 193-203, 1972.

12 "La alteridad para E. Levinas no es un concepto abstracto, sino un momento estructural del sentir humano. El yo y la libertad se alzan en esta específica sensibilidad humana por la que el otro es otro antes que concepto. La noción idealista de sujeto sólo es posible desconociendo que 'el mundo sensible desborda la libertad de la representación'. El rostro, el cara-cara son expresiones plásticas de una alteridad insalvable e irreductible del sentir humano. Esta alteridad es precisamente el fundamento de la ética.” COROMINAS, Jordi. Ética primera: aportación de X. Zubiri al debate ético contemporáneo. Bilbao: Desclée de Brouwer, 2000. p. 92.

13 FARRELL, Martin D. Algunas maneras de entender a la neutralidad. Doxa, p. 15-16, 1994. p. 183. Disponível em: <http:// www.cervantesvirtual.com/servlet/SirveObras/01361620824573839199024/cuaderno15/voll/doxa15_09.pdf>. Acesso em: 3 ago. 2005.

14 PENNA, Antônio Gomes; NALINI, José Renato (Coord.). Uma nova ética para o juiz: São Paulo: RT, 1994. p. $30-31$.

15 ZIMMERMANN, Roque. América Latina o não ser. 2. ed. Rio de Janeiro: Vozes, 1987. p. 27.

16 PAJARDI, Piero. I provvedimenti d'urgenza atipici nel processo civile. Milano: Pirola, 1988. p. 283.

17 COMPARATO, Fábio Konder. Papel do jurista num mundo em crise de valores. Revista dos Tribunais, São Paulo, ano 84, v. 713, mar. 1995. p. 283. 
Humanizar o processo é personalizá-lo; enfim, socializá-lo com os ares generosos da solidariedade. ${ }^{18}$ Numa ética filosófica material, procura-se afirmar que o ser humano e sua produção, reprodução e desenvolvimento são referência para o exercício da atividade jurisdicional e que as questões processuais não estão enclausuradas, apenas, no âmbito jurídico e dogmático da relação jurídica processual, pois extrapolam os limites do processo, como no caso das gestantes, em que o seu entorno, em especial a criança, faz a diferença no momento de se escolher determinada decisão.

Essa postulação humanitária de uma nova leitura do princípio da (im)parcialidade reclama o efetivo reconhecimento das diferenças existentes entre as pessoas, para que se possa vislumbrar uma decisão final équo e justa.

Seguindo-se o critério apresentado por Maria Teresa de Melo Ribeiro, pode-se resumir a aplicação principiológica da imparcialidade nos seguintes termos: (a) a tendência para reservar ao princípio da imparcialidade um entendimento amplo e abrangente, do qual resulta a atribuição ao princípio da imparcialidade de um conteúdo simultaneamente negativo e positivo; (b) a tendência para identificar a vertente positiva com a obrigação de o Poder Judiciário considerar todos os interesses legalmente relevantes no caso concreto, sejam eles públicos ou privados; (c) a tendência para considerar o princípio da imparcialidade um princípio jurídico vinculativo de toda atividade jurisdicional; (d) a tendência para ligar o princípio da imparcialidade à realização de um ideal de justiça. ${ }^{19}$

Focando-se nessa perspectiva positiva do princípio da imparcialidade do juiz, recomenda-se uma conduta ética universal do juiz na relação jurídica processual de maneira que tal conduta reconheça as necessidades das vítimas de um sistema totalizador, e que, a partir dessas vítimas, possa promover um equacionamento racional visando a um processo justo e équo. ${ }^{20}$

E essa ética de caráter universal somente pode decorrer, conforme afirma o filósofo argentino, radicado no México, Enrique Dussel, da constatação antropológica de que o ser humano é o único ser vivente responsável pela sua própria vida e da “[...] obligación universal de producir, reproducir y desarrollar la vida humana concreta de cada sujeto ético em comunidad”. ${ }^{21}$ Esse princípio caracteriza-se por ser um princípio a priori universal e também fundamental, ainda que não suficiente, para a construção de uma ética da libertação, isto é, "[...] de una ética que intenta justificar filosoficamente las luchas de los oprimidos".22

É na produção, reprodução e desenvolvimento da vida humana que Enrique Dussel estabelecerá o fundamento material de sua ética filosófica da vida. A vida humana, portanto, é o conteúdo específico da ética. ${ }^{23}$ Trata-se de um critério que tem por objeto produzir, reproduzir e desenvolver a vida humana concreta de cada sujeito ético em comunidade. Para Enrique Dussel, esse critério serve de fundamentação a um princípio que, por sua vez, terá pretensão de universalidade, realizando-se por meio das culturas e dos valores a serem perseguidos. ${ }^{24}$

18 MORELLO, Augusto. El proceso justo. Buenos Aires: Abeledo-Perrot, 1994. p. 16-17.

19 RIBEIRO, Maria Teresa de Melo. O princípio da imparcialidade da administração pública. Coimbra: Almedina, 1996. p. 108-109.

20 O conteúdo material, também, faz parte do pensamento de Pietro Barcellona, nos seguintes termos: "Bastaría con que el jurista se limitase a salir del círculo mágico de sus fórmulas abstractas, del cerrado horizonte de las normas, y afrontase directamente el problema de los contenidos materiales de la justicia. Pero actuando de esta forma, está claro, debería renunciar a la aparente esterilidad axiológica de sus construcciones, a la indiferencia ante los valores, a la neutralidad frente a los conflictos. Debería sumergirse en la política, en la ética, en la práctica". BARCELLONA, Pietro; HART, Dieter; MÜCKENBERGER, Ulrich. La formación del jurista: capitalismo monopolístico y cultura jurídica. Madrid: Civitas, 1993. p. 44.

21 COROMINAS, Jordi. Ética primera: aportación de X. Zubiri al debate ético contemporáneo. Bilbao: Desclée de Brouwer, 2000 . p. 74. 22 COROMINAS, Jordi. Ética primera: aportación de X. Zubiri al debate ético contemporáneo. Bilbao: Desclée de Brouwer, 2000. p. 74.

23 “[...] O ser humano acede à realidade que enfrenta dia a dia a partir do âmbito de sua própria vida. A vida humana não é um fim nem um mero horizonte mundano-ontológico. A vida humana é o modo de realidade do sujeito ético (que não é o de uma pedra, de um animal irracional ou da 'alma' angélica de Descartes), que dá o conteúdo a todas as suas ações, que determina a ordem racional e também o nível das necessidades, pulsões e desejos, que constitui o marco dentro do qual se fixam fins. Os 'fins' (relativamente à razão instrumental formal weberiana) são ‘colocados' a partir das exigências da vida humana.” DUSSEL, Enrique. Ética da libertação na idade da globalização e da exclusão. Rio de Janeiro: Vozes, 2000. p. 131.

24 DUSSEL, Enrique. Ética da libertação na idade da globalização e da exclusão. Rio de Janeiro: Vozes, 2000. p. 93 
Em razão desse princípio ético material,

[...] toda norma, ação, microestrutura, instituição ou eticidade cultural têm sempre e necessariamente como conteúdo último algum momento da produção, reprodução e desenvolvimento da vida humana em concreto. ${ }^{25}$

A Ética da concreção é a ética moderna, isto é:

A ética do nosso tempo é uma ética existencial, que põe acima de tudo a pessoa humana, não como abstração, à maneira de Boécio, mas como uma concreção vital, como valor fonte dos demais valores. ${ }^{26}$

É com base no critério material (vida humana concreta) que se devem subsumir os outros aspectos materiais (como os valores, a lógica das pulsões etc.). Esse critério material, igualmente, permite fundamentar ou desenvolver um princípio ético universal, supracultural. ${ }^{27}$

Esse critério de produção, reprodução e desenvolvimento da vida humana não é algo a ser imputado à consciência humana, a um certo "consciencialismo" moderno que faz perder o sentido da corporalidade orgânica da existência ética. ${ }^{28}$ Se a espécie humana está formatada, neurocerebralmente, para a preservação e desenvolvimento da vida humana, tal critério não é diferente nas relações sociais, como é o caso do direito e do processo, razão pela qual a atuação do juiz deverá ser guiada por esse "critério de verdade" prática. ${ }^{29}$

Esse critério material sobre o qual se funda a ética, produção reprodução e desenvolvimento da vida humana, é universal, não solipsista, mas comunitário. Diz respeito a uma comunidade de vida.

Se a humanidade perdesse essa consciência do outro, diante de sua miséria, de sua impotência social, econômica e cultural, poderia precipitar-se num suicídio coletivo. ${ }^{30}$

O reconhecimento do outro, como forma de produção, reprodução de desenvolvimento da vida humana, transforma-se de um critério de verdade prática numa exigência ética: no dever-reconbecer. ${ }^{31}$

O Poder Judiciário, como instrumento dessa ética existencial, pois é uma instituição que, também, atua mediante princípios éticos, deve pautar sua ação prática racional, no momento de realizar sua atividade básica e essencial, segundo o princípio material universal de produção, reprodução e desenvolvimento da vida bumana. Para tanto, deve (princípio ético) reconhecer as desigualdades sociais, econômicas e culturais, que possam existir no âmbito da relação jurídica processual. Em outras palavras, deve reconhecer o "outro" vítima potencial de um sistema totalizado.

25 DUSSEL, Enrique. Ética da libertação na idade da globalização e da exclusão. Rio de Janeiro: Vozes, 2000. p. 93

26 REALE, Miguel. A ética do juiz na cultura contemporânea. In: NALINI, José Renato (Coord.). Uma nova ética para o juiz: São Paulo: RT, 1994. p. 146.

27 “De fato, não há ‘um horizonte último comum’ cultural, mas há um princípio material universal interno a cada uma e a todas as culturas, e isto Taylor não vê. Não é um 'horizonte’; é um modo de realidade: a própria vida humana.” DUSSEL, Enrique. Ética da libertação na idade da globalização e da exclusão. Rio de Janeiro: Vozes, 2000. p. 122.

28 DUSSEL, Enrique. Ética da libertação na idade da globalização e da exclusão. Rio de Janeiro: Vozes, 2000. p. 95.

29 "Do ponto de vista cerebral, o sistema avaliativo/afetivo cerebral responde da seguinte forma: em primeiro lugar responde às necessidades objetivas primeiras; em segundo lugar, articula-se com o nível linguístico-cultural e histórico; em terceiro lugar responde às exigências superiores e culturais universais de uma ética crítica.” DUSSEL, Enrique. Ética da libertação na idade da globalização e da exclusão. Rio de Janeiro: Vozes, 2000. p. 104.

30 "O projeto da libertação dos oprimidos e dos excluídos é aberto, partindo da exclusão do outro e indo mais além (jenseits) de qualquer situação apresentada. A estruturação de alternativas - mesmo que fosse necessária (o que não podemos descartar a priori) a de uma utopia ou a de uma nova sociedade — não consiste na 'aplicação' de algum modelo ou situação ideal ou transcendental, nem tampouco na execução autêntica de um determinado 'mundo da vida' (quer seja ele o moderno ou outro diferente), muito menos se for idealizado como efeito indestrutível de uma lógica necessária (a da teologia ou razão histórica de Hegel ou a do marxismo standart ou de Stalin); mas deverá ser uma 'des-coberta' responsável, como resposta à 'interpelação' do outro, dentro de um lento processo de prudência (em que a teoria de uma 'comunidade de comunicação real' — que racional e processualmente chega a um consenso de validade intersubjetiva — nos ajuda a compreender melhor o progredir seletivo da fronésis de libertação), durante o qual o filósofo (tal como 'intelectual orgânico' de Gramsci deve tratar com seriedade as motivações ética (com Taylor) da libertação dos oprimidos e excluídos.” DUSSEL, Enrique. Filosofia da libertação: crítica à ideologia da exclusão. 2. ed. São Paulo: Paulus, 1995. p. 119-120.

31 DUSSEL, Enrique. Ética da libertação na idade da globalização e da exclusão. Rio de Janeiro: Vozes, 2000. p. 141. 
Essa ética filosófica está expressamente consignada e fundamentada no próprio texto constitucional brasileiro, quando afirma, em seu art. 1. ${ }^{\circ}$, que a República Federativa do Brasil, da qual faz parte o Judiciário, constitui-se em um Estado Democrático de Direito, e tem como fundamento a dignidade da pessoa bumana, ou seja, a produção, reprodução e desenvolvimento da vida humana.

Por sua vez, em seu art. 3. ${ }^{\circ}$, a Constituição Federal estabelece que constituem objetivos fundamentais da República Federativa do Brasil a construção de uma sociedade livre, justa e solidária, mediante a erradicação da pobreza e da marginalização, conjugando esforços no sentido de reduz̧ir as desigualdades sociais e regionais. Em outras palavras, a Constituição Federal exige uma ética universal material no sentido de que os órgãos e instituições da República Federativa do Brasil ajam de forma a produzir, reproduzir e desenvolver a vida bumana.

Por tudo isso:

[...] propomos a seguinte descrição inicial do que chamaremos princípio material universal da ética, princípio da corporalidade como 'sensibilidade' que contém a ordem pulsional, cultural-valorativa (hermenêutica-simbólica), de toda norma, ato, microfísica estrutural, instituição ou sistema de eticidade, a partir do critério da vida humana em geral: aquele que atua eticamente deve (como obrigação) produzir, reproduzir e desenvolver autorresponsavelmente a vida concreta de cada sujeito humano, numa comunidade de vida, a partir de uma 'vida boa' cultural e histórica (seu modo de conceber a felicidade, com uma certa referência aos valores e a uma maneira fundamental de compreender o ser como deverser, por isso também, com pretensão de retidão) que se compartilha pulsional e solidariamente, tendo como referência última toda a humanidade, isto é, é um enunciado normativo com pretensão de verdade prática e, em além disso, com pretensão de universalidade. ${ }^{32}$

Mas, diante das desigualdades sociais, econômicas e culturais, somente se pode postular um critério/ princípio da produção, reprodução e desenvolvimento da vida humana no âmbito processual, sob um aspecto material positivo, desde que se perceba o surgimento do "rosto" que se destaca na ordem social vigente, e que representa as vítimas não intencionais ou mesmo intencionais de um determinado sistema totalizado e porque não dizer globalizado. Isto é, "[...] o rosto sensível do outro homem, que tem fome e sangue, encontra-se para além do sistema onde o ser é o pensar [...]. O 'tu', outro homem, é exterior ao âmbito ser-pensar [...].”.33

Enrique Dussel, voltado para a efetiva existência de vítima de um determinado sistema, reporta-se, a partir dessa vítima, à verdade do sistema totalizador que começa a ser descoberta como não verdade, ao válido como não válido, e ao factível como não eficaz. A construção temática passa do âmbito da positividade para a negatividade da existência de vítima.

A ética propriamente dita é a que a partir das vítimas pode julgar, criticamente, a "totalidade" de um sistema de eticidade. A partir das vítimas pode julgar e pôr em dúvida a verdade e a legitimidade da concepção ontológica da imparcialidade do juiz.

É a partir da exterioridade de uma dada totalidade, em que se situam as vítimas, que se estabelece uma consciência crítica do sistema de eticidade dado. As vítimas "[...] são reconhecidas como sujeitos éticos, como seres humanos que não podem reproduzir ou desenvolver sua vida, que foram excluídos da participação na discussão [...]". ${ }^{34}$ No sistema de eticidade, “o bem" inverte-se no "mal" e causa dor, sofrimento, infelicidade ou a própria morte das vítimas.

É na alteridade do outro “como outro" que o sistema ético crítico se impõe. É a alteridade da vítima

32 DUSSEL, Enrique. Ética da libertação na idade da globalização e da exclusão. Rio de Janeiro: Vozes, 2000. p. 143.

33 DUSSEL, Enrique. Ética da libertação na idade da globalização e da exclusão. Rio de Janeiro: Vozes, 2000. p. 148.

34 " [...] o sistema de eticidade vigente, que era para a consciência ingênua (que pode ser científica, ocupar a função de autoridade política ou econômica, ou ainda ser membro da elite moral do sistema, a 'raça sacerdotal' de Nietzsche) a medida do 'bem' e do 'mal', converte-se diante da presença de suas vítimas, enquanto sistema, no perverso (o 'mau'). É toda a questão do 'fetichismo' de Marx, a 'inversão dos valores' de Nietzsche, a descoberta do 'superego' repressor em Freud, a sociedade 'excludente' de Foucault, a 'dialética negativa' em Adorno e 'totalidade’ de Lévinas.” DUSSEL, Enrique. Ética da libertação na idade da globalizaç̧ão e da exclusão. Rio de Janeiro: Vozes, 2000. p. 303. 
como oprimida (classe) ou como excluída (mulher pobre e subjugada no sistema carcerário). É o descobrimento do "outro" que se encontra encoberto pelo mito da modernidade. Trata-se de uma ética que demonstra o terror de uma razão fechada na totalidade, entre outras, a razão da modernidade..$^{35}$

A responsabilidade pelo outro conduz a uma filosofia de vida em que se revela um profundo compromisso com a vida. A vida é realizada e confirmada segundo a concretude de cada dia.

Para Martin Buber, o projeto da filosofia é explicitar a concretude vivida da existência humana a partir do próprio interior da vida. ${ }^{36}$

No interior dessa filosofia de vida, Emmanuel Lévinas procura construir a subjetividade e a intersubjetividade humanas num nível pré-originário, o qual seria anterior a qualquer tematização. "O existente humano singular e concreto já se move num âmbito anterior ao mundo como horizonte de compreensão". ${ }^{37}$ Existe um nível anterior ao ser e à sua obra de ser, e encontrá-lo e nele se refugiar é o que se entende por sair do ser sem apelar para sua negação. Sair do ser é criar um intervalo no ser, sem, contudo, negá-lo. O primeiro, portanto, não é ontológico, não o ser, não é a aventura de compreender e do saber, é algo diferente. É a ética como anterior à ontologia. ${ }^{38}$

Em defesa da ética como filosofia primeira, Emmanuel Lévinas sustenta ou identifica a ontologia com o dogmatismo, e demonstra que a crítica é anterior ao dogmatismo. A ética é crítica, portanto, a ética é anterior a ontologia fundamental que é dogmática. O dogmatismo é uma postura epistemológica existente no interior da ontologia em que se afirma a liberdade cognoscente do sujeito diante da exterioridade do objeto cognoscível. Por isso: "Ser livre significa que o saber é uma relação do próprio com o outro onde o outro se reduz ao próprio [...] onde o pensamento se refere ao outro, mas onde o outro já não é outro enquanto tal, onde ele já é o próprio, já meu". ${ }^{39}$

O sujeito se reconhece ser humano ao mesmo tempo em que reconhece ao outro como ser humano, e, por isso, lhe atribui sua própria "consciência humana", o que explica que:

[...] a cada separación o divergencia con el otro en los combates y enfrentamientos, el individuo tenga, espontáneamente, tendencia a romper la pertenencia común, a priva al otro de su conciencia moral, a rechazarlo, simbólica o legalmente, fuera de la humanidad. ${ }^{40}$

Transportando-se o pensamento de Emmanuel Lévinas para a ética da libertação de Enrique Dussel, pode-se afirmar que o sistema de eticidade corresponde a um nível ontológico de totalidade, que começa a ser questionado, refutado, por um juízo ético material da razão crítica negativa que se encontra na exterioridade do rosto das vítimas.

Portanto, na perspectiva de Emmanuel Lévinas, a ética é metafísica. A sensibilidade (pré-ontológica) anterior a toda inteligibilidade parte de uma concepção do sujeito que deve reconhecer o outro como exterioridade (pós-ontológica).

Eis aí, portanto, a fundamentação ética preconizada no HC n. Habeas Corpus n. 143.641, em que o Supre-

35 A perspectiva filosófica formulada neste trabalho vem ao encontro da nova tendência do processo penal moderno, em que se levam em consideração as vítimas. Segundo Antonio Beristain: "Hasta finales del siglo XX, el centro del proceso lo ocupan, cada día más las víctimas. Por otra parte, ante la policía, los jueces y los peritos, las víctimas sufrían una segunda victimación que ahora se critica severamente, y, con frecuencia, se procura evitar. En algunos casos se llega más adelante: se va logrando que la meta principal del proceso no sea la pena al condenado sino la reparación a las víctimas" BERISTAIN, Antonio. Nuevo proceso penal desde las víctimas. In: PIERANGELI, José Henrique (Coord.). Direito criminal. Belo Horizonte: Del Rey, 2001. p. 26. Evidentemente que neste trabalho não se restringe a análise da vítima apenas na perspectiva do sujeito que sofre um dano em face do delito, mas em face da totalidade dos sujeitos envolvidos na relação jurídica processual.

36 BUBER, Martin. Eu e tu. 8. ed. São Paulo: Cortez \& Moraes, 1974. p. xxviii.

37 ANDRE, Manuel da Costa. Sobre as proibições de prova em processo penal. Coimbra: Coimbra, 1992. p. 24.

38 ANDRE, Manuel da Costa. Sobre as proibições de prova em processo penal. Coimbra: Coimbra, 1992. p. 25.

39 LÉVINAS, Emmanuel. Transcendência e inteligibilidade. Lisboa: Edições 70, 1984. p. 14.

40 MORIN, Edgar; PIATTELLI-PALMARINI, Massimo. La unidad del hombre: interdisciplinariedad y ciencias humanas. Madrid: Tecnos, 1983. p. 211. 
mo Tribuna Federal reconheceu a ética da racionalidade do outro como uma sensibilidade pré-ontológica.

Por meio de uma racionalidade crítica que rompe com a totalidade processual dominante (cárcere a qualquer custo), o juiz deve abandonar sua subjetividade solipsista de apenas realizar um ato de conhecimento no âmbito de atividade jurisdicional, para, por meio de sua sensibilidade, reconhecer a exterioridade das vítimas, das diferenças sociais, econômicas e culturais.

É possível ao juiz libertar-se da dogmática de seu "solipsismo", de sua "subjetividade egoística", no seu conforto da imparcialidade como neutralidade, para alcançar o "outro" que se encontra num âmbito transcendental, e confirmar a sua responsabilidade que é pré-ontológica.

O juiz não deve tematizar o outro (vítima inferiorizada na relação jurídica processual), mas deixar transparecer um desejo metafísico de proferir uma decisão équo e justa, pois o juiz, em relação às vítimas do sistema, tem uma responsabilidade ética pré-originária à totalidade do sistema jurídico dominante.

Tendo em vista essa responsabilidade ética pré-originária não tematizadora do outro, o método que antecede a própria dialética (que para Enrique Dussel seria o método por excelência da totalidade), a ser desenvolvido pré-originariamente no processo, seria o método analítico que permite a abertura efetiva ao outro e, concomitantemente, a derrubada do sistema e da totalidade cerrada, para o fim de liberar o outro negado em sua dignidade.

\section{Considerações finais}

O Supremo Tribunal Federal, ao proferir decisão, no Habeas Corpus n. 143.611, em favor das mulheres presas preventivamente e que ostentam a condição de gestantes, de puérperas ou de mães de crianças sob sua responsabilidade, deixou, de certa forma, evidenciado quais seriam os fundamentos da dogmática jurídica penal, constitucional, criminológica, sociológica e do direito das gentes que serviram de base para a proteção coletiva dos pacientes.

Porém, é possível constar da complexidade dos argumentos introduzidos no referido julgamento um fundamento ético material que justifica, filosoficamente, a conclusão adotada no remédio constitucional.

Trata-se de um fundamento em que a ética material é inserida como filosofia primeira, antes mesmo da ontologia. E essa ética é uma ética de concreção, que coloca, acima de tudo, a dignidade da mulher presa preventivamente como critério de produção, reprodução e desenvolvimento da pessoa humana.

Em razão dessa ética material, como filosofia primeira, justifica-se um novo estereótipo da representação simbólica da Justiça, no sentido de que a venda da deusa da Justiça seja retirada para que se possa reconhecer no processo a racionalidade do outro, a sua diferença sociocultural-político-econômica. A balança, diante da realidade latino-americana deve ser desequilibrada, a fim de representar as desigualdades sociais, econômicas e culturais existentes num continente regrado por injustiças sociais. E a espada, por fim, deve ser substituída por uma "lupa", para que se possam avistar as concepções ideológicas que existem por trás de um determinado ordenamento jurídico de cunho sexista e discriminatório.

\section{REFERÊNCIAS}

ALBUQUERQUE, Aline S. de Oliveira; BARROS, Julia Schirmer. Caso Alyne Pimentel: uma análise à luz da abordagem baseada em direitos humanos. Revista do Instituto Brasileiro de Direitos Humanos, Fortaleza, n. 12, jul. 2016. 
ANDRE, Manuel da Costa. Sobre as proibições de prova em processo penal. Coimbra: Coimbra, 1992.

BARCELLONA, Pietro; HART, Dieter; MÜCKENBERGER, Ulrich. La formación del jurista: capitalismo monopolístico y cultura jurídica. Madrid: Civitas, 1993.

BERISTAIN, Antonio. Nuevo proceso penal desde las víctimas. In: PIERANGELI, José Henrique (Coord.). Direito criminal. Belo Horizonte: Del Rey, 2001.

BRASIL. Conselho Nacional de Justiça. PANORAMA de Acesso a 4 Revisado Habeas Corpus 143641 / SP Justiça no Brasil, 2004 a 2009. Brasília: Conselho Nacional de Justiça, 2011.

BRASIL. Ministério da Justiça. Infopen Mulheres. Levantamento nacional de informacões penitenciárias. 2014. p. 18-19. Disponível em: <https://www.justica.gov.br/news/estudo-traca-perfil-da-populacao-penitenciariafeminina-no-brasil/relatorio-infopen-mulheres.pdf>. Acesso em: 7 jun. 2018.

BUBER, Martin. Eu e tu. 8. ed. São Paulo: Cortez \& Moraes, 1974.

COMPARATO, Fábio Konder. Papel do jurista num mundo em crise de valores. Revista dos Tribunais, São Paulo, ano 84, v. 713, p. 283, mar. 1995.

COROMINAS, Jordi. Ética primera: aportación de X. Zubiri al debate ético contemporáneo. Bilbao: Desclée de Brouwer, 2000.

DUSSEL, Enrique. Ética da libertação na idade da globalização e da exclusão. Rio de Janeiro: Vozes, 2000.

DUSSEL, Enrique. Filosofia da libertação: crítica à ideologia da exclusão. 2. ed. São Paulo: Paulus, 1995.

FARRELL, Martin D. Algunas maneras de entender a la neutralidad. Doxa, p. 15-16, 1994. Disponível em: <http://www.cervantesvirtual.com/servlet/SirveObras/01361620824573839199024/cuaderno15/voll/ doxa15_09.pdf>. Acesso em: 3 ago. 2005.

FAZZALARI, Elio. La imparzialità del giudice. Rivista di Dirito Processuale, Padova, Cedam, n. 2, p. 193-203, 1972.

LÉVINAS, Emmanuel. Transcendência e inteligibilidade. Lisboa: Edições 70, 1984.

MACHADO FILHO, H. União Europeia, Brasil e os desafios da agenda do desenvolvimento sustentável. In: SOBRENOME, Nome. Dos objetivos do milênio aos objetivos do desenvolvimento sustentável: lições aprendidas e desafios. Rio de Janeiro: Konrad Adenauer Stiftung, 2016.

MORELLO, Augusto. El proceso justo. Buenos Aires: Abeledo-Perrot, 1994.

MORIN, Edgar; PIATTELLI-PALMARINI, Massimo. La unidad del hombre: interdisciplinariedad y ciencias humanas. Madrid: Tecnos, 1983.

PAJARDI, Piero. I provvedimenti d'urgenza atipici nel processo civile. Milano: Pirola, 1988.

PENNA, Antonio Gomes; NALINI, José Renato (Coord.). Uma nova ética para o juiz: São Paulo: RT, 1994.

REALE, Miguel. A ética do juiz na cultura contemporânea. In: NALINI, José Renato (Coord.). Uma nova ética para o juiæ: São Paulo: RT, 1994.

REQUJO PAGÉS, J. L. Jurisdicción e independencia judicial. Madrid: Centro de Estudios Constitucionales, 1989.

RHODE, Deborah L. Access to justice. New York: Oxford, 2004.

RIBEIRO, Maria Teresa de Melo. O princípio da imparcialidade da administração pública. Coimbra: Almedina, 1996.

RICOEUR, Paul. Interpretação e ideologias. Rio de Janeiro: Livraria Alves, 1977.

ROCHA, Leonel Severo. A problemática jurídica: uma introdução transdisciplinar. Porto Alegre: Fabris, 1985. 
ROCHA, Lilian Rose Lemos; CARDOZO, José Eduardo. Precariedade do sistema penitenciário brasileiro como base temática para a proibição ou legalização das drogas. Revista Brasileira de Políticas Públicas, v. 7, n.3, dez. 2017.

RORTY, Richard. A filosofia e o espelho da natureza. 3. ed. Rio de Janeiro: Relume Dumará, 1994.

SAMUELS, Andrew. Jung e os pós-junguianos. Rio de Janeiro: Imago, 1989.

SANTIAGO, Silviano. Pósfácio. In: LYOTARD, Jean-François. A condição pós-moderna. 7. ed. Rio de Janeiro: José Olympio, 2002.

SANTOS, Boaventura Souza. O discurso e o poder. Estudos em homenagem ao Prof. Doutor J. J. Teixeira Ribeiro. Coimbra: II Iuridica, 1979.

SATTA, Salvatore. Astensione del giudice. Enciclopedia del diritto. Milano: Giuffrè, 1958. t.3.

SCHMIDT, Eberhard. Los fundamentos teóricos y constitucionales del derecho procesal penal. Buenos Aires: Bibliográfica Argentina, 1957.

SCHOEPFLIN, Marurizio. L'amore ama il Bene, parola di Lévinas. Disponível em: <http://lgxserver.unib.it/ lei/rassegna/010512a.htm>. Acesso em: 26 mar. 2004.

SCILLITANI, Marco. Il giusto processo: associazione tra gli studiosi del proceso penale. Milano: Giuffrè, 1998.

SOARES, B. M.; ILGENFRITZ, I. Prisioneiras: vida e violência atrás das grades. Rio de Janeiro: Garamond, 2002.

SOUZA, Luciana Cristina. Dignidade humana na webesfera governamental brasileira. Revista Brasileira de Políticas Públicas, v. 7, n. 3, dez. 2017.

UN WOMEN. A gender perspective on the impact of drug use, the drug trade, and drug control regimes. 2014. p. 3435. Disponível em: < https://www.unodc.org/documents/ungass2016/Contributions/UN/Gender_and_ Drugs_-_UN_Women_Policy_Brief.pdf>. Acesso em: 7 jun. 2018.

ZIMMERMANN, Roque. América Latina o não ser. 2. ed. Rio de Janeiro: Vozes, 1987. 
Para publicar na revista Brasileira de Políticas Públicas, acesse o endereço eletrônico www.rbpp.uniceub.br

Observe as normas de publicação, para facilitar e agilizar o trabalho de edição. 